\title{
Evaluation of the Efficiency of Three Different Types of Bonded Retainers Used in Orthodontics
}

\begin{abstract}
LUMINITA LIGIA VAIDA ${ }^{1}$, DANA FESTILA ${ }^{2 *}$, ABEL EMANUEL MOCA ${ }^{1 *}$, BIANCA IOANA TODOR ${ }^{1}$, BIANCA NEGRUTIU1, ANTONIA MIHAIU3 ${ }^{3}$, MIRCEA GHERGIE², CLAUDIA TEODORA J UDEA PUSTA ${ }^{4}$, ALEXANDRINA MUNTEAN ${ }^{3}$

IUniversity of Oradea, Faculty of Medicine and Pharmacy, Department of Dentistry, 1 Universitatii Str., 410087, Oradea, Romania 'University of Medicine and Pharmacy luliu Hatieganu, Faculty of Dental Medicine, Orthodontic Department, 31 Avram lancu Str., 400001, Cluj-Napoca, Romania

3University of Medicine and Pharmacy Iuliu Hatieganu, Faculty of Dental Medicine, Pediatric Dentistry Department, 31 Avram Iancu Str., 400001, Cluj-Napoca, Romania

${ }^{3}$ University of Oradea, Faculty of Medicine and Pharmacy, Department of Morphological Disciplines, 1 Universitatii Str., 410087, Oradea, Romania

The bonded retainers are mainly used for the mandibular dental arch. This study aims to analyse the efficiency of three different types of fixed retainers, multistranded 0.0195-in wire, Australian wire and Starbond CoS laser sintering retainer, as well as the relapse rate for each type of retainer used over a period of two years. The sample consisted of 159 patients, of whom 55 patients (Group 1) had multistranded 0.0195-in wire, 53 patients (Group 2) Australian wire, and 51 patients (Group 3) laser-sintering retainers. 16 partial or complete detachments were recorded in the first year of the retention phase, of which 5 retainers from Group 1, 6 from Group 2 and 5 from Group 3, in the case of lasers-sintering retainers only total detachments were noticed, and 2 of the multistranded retainers suffered deformations. The results show that there are no statistically significant differences between the three types of retainers in the first year of retention period, but lasersintering retainer had a statistically significant better evolution compared to multistranded retainer $(p=0.018$ ) after two years of retention. No statistically significant differences were found between the three types of retainers regarding the rate of relapse (10.9\% for Group 1, 7.5\% for Group 2 and 7.8\% for Group 3). In the second year of the retention phase, the relapse rate did not present a statistically significant change from the first year, but it increased slightly in patients from Group 1 and it decreased slightly in patients from Group 3. No fixed retention system is perfect, everything has its drawbacks.
\end{abstract}

Keywords: bonded retainer, fixed retainer, multistranded wire, Australian wire, laser sintering

The orthodontic treatment generally involves the completion of two major phases, the active phase and the passive phase, both being equally important. The final goal of the active orthodontic treatment is correcting all dentofacial alterations caused by various malocclusions. The active treatment usually extends over a period of $12-24$ months, but more treatment time might be necessary in difficult cases. This phase should be followed by passive orthodontic treatment, called the retention phase, which aims at carefully stabilizing the results obtained in the first phase. This stage extends over a period that varies from 12 years to 10 years or more, lifetime permanent retention being considered the only reliable way to prevent relapse [1-3]. Failure to follow up the retention phase results in partial or total relapse of the initial malocclusion, because malocclusions have a great potential for relapse, especially in the anterior segments of the dental arches, and relapse is quite unpredictable [4-7].

The retention phase also includes two subphases, the first being called the retention in which it is intended to maintain the therapeutic outcome, but also the reorganization of the periodontal ligament (takes over a 3 to 4 months period), remodelling of the gingival collagenfiber network (needs 4 to 6 months), and remodelling of the elastic supracrestal fibers (takes more than 7 months); the second subphase of retention, called the post-retention phase lasts for the rest of the patient's life [8. 9]. Literature describes a wide variety of retainers; a first grading can be done in removable and fixed retainers [10]. Removable retainers include: vacuum-formed retainers or Essix retainers, Hawley retainers or similar plates using thermoplastic or thermo-set resins, wraparound, positioners [11-14]. The fixed or bonded retainers are usually used in the lower dental arch, comprising 2 to 8 teeth, and more rarely in the upper dental arch, most often ranging from 2 to 4 upper incisors. The fixed retainers are classified as polyethylene and fiber-reinforced resin composites [10] . Specialised literature mentions many types of composite for bonding and wire combinations for fixed lingual retainer fabrication: multistranded 0.0215 - or 0.0195 -in diameter wire or a thick 0.020- to 0.032 -in round stainless-steel wire retainers (used also in the field of periodontology as periodontal splint) [15-17]. Currently, the most preferred multistrand stainless steel wires are 3-stranded 0.0195-in wire or 5-stranded 0.0215-in wire [18]. The fixed retainers are bonded to 2 mandibular teeth (canine-and-canine bonded retainer), but usually they are bonded to 3 or more teeth, most frequently the mandibular incisors and canines (canine-to-canine bonded retainer) or the maxillaryincisors. The canine-and-canine bonded retainers are rigid and thus they could be effective in maintaining inter-canine width but allow individual tooth rotation.

Three-stranded twisted round wire is round in crosssection and formed from 3 wires made from stainless steel that are twisted (fig.1-a) [19]. The Australian wire (A) Wilcock Australian wire) is a stainless steel wire made by G\&H Wire Company that recomends this wire as the finest stainless steel of its kind with extraordinary resilience 


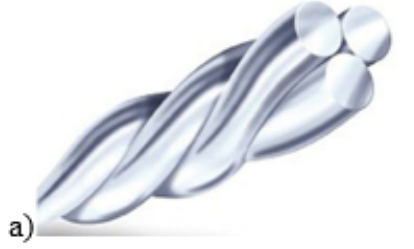

b)
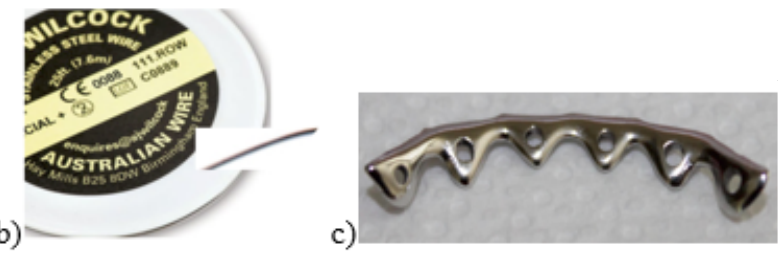

Fig. 1. a) Three stranded twisted round wire, after Green (2015) [19]; b) Australian wire - G\&H Wire Company [20]; c) Starbond CoS laser-sintering retainer simplynotfound in any other orthodontic wire product (fig. 1-b) [20]. A new type of bonded retainer is Starbond COS laser sintering retainer, that implies a special manufacturing technology (fig. 1-c).

The multistranded wire and Australian wire are obtained from stainless steel (G\&H Wire Company) having a chemical nature of metal. The multistranded wire is made from 304 stainless steel, and Australian wire is made from 302 stainless steel (table 1) [20, 21]. Starbond CoS laser sintering retainer is obtained from Starbond CoS Powder made by $\mathrm{S} \& \mathrm{~S}$ Scheftner $\mathrm{GmbH}$. Starbond CoS Powder is based on the proven dental bonding alloy Starbond CoS [22]. Starbond CoS is a cobalt-chrome bonding alloy (tabel 1) which enables the production of high-quality dental restorations in mass production, in 3D printing, using selective laser melting (SLM) systems or selective laser sintering technology (SLS). SLS is a 3D printing technology that has some advantages such as: no support is needed during manufacturing, materials can be reused, the component parts have high precision, the great interest drawn by it in the medical field being, therefore, understood $[23,24]$. Its main indications in dentistry field are for manufacturing dentures, frameworks for metal ceramic veneers, partial dentures as well as primary and secondary parts for combined dentures. Starbond CoS has extremely corrosion resistance. Starbond CoS Powder 30 has grain size of the alloy powder of $+10 /-30 \mu \mathrm{m}$ [25].

Studies have shown that bonded retainers are more comfortable for the patient than removable retainers and provide greater safety in maintaining the therapeutic outcome, with the great advantage of being unnoticeable $[17,26]$. Many child and adolescent patients who have successfully completed the orthodontic treatment have a higher level of self-esteem and current self-related cognitions, and thus, reaching their initial goal of improving their dento-facial appearance, they are not affected by the retention phase $[27,28]$. The use of bonded retainers has the advantage of requiring minimum patient compliance.

The inspired choice of the type of wire, respectively the type of fixed retainer can maximize the success of the orthodontic treatment during retention phase [29].
The purpose of this study was to compare the efficiency of three different types of bonded retainers used in the retention phase after the orthodontic treatment with fixed appliances for a period of two years with regards to the rate of the retainer detachment, deformation or breakage and the rate of relapse.

\section{Experimental part \\ Subjects}

The sample consisted of 315 orthodontic patients, aged 12-18 years (mean age 14 years 5 months), who were diagnosed with various malocclusions which were treated using fixed orthodontic appliances and who had the active orthodontic treatment completed in 2016. The patients enrolled in the study were selected according to the following criteria: no prior orthodontic treatment, patients with previous fixed orthodontic appliances to both dental arches or at least to the lower dental arch, patients with various malocclusions but with crowding in the anterior lower teeth area before the orthodontic treatment, with lower dental arch space deficiency more than $3 \mathrm{~mm}$, achievement of optimum occlusion relationships (correct position of teeth on arches, dental alignment, proper static and dynamic occlusion relationships), patients who had canine-to-canine retainers for the retention phase (retainer bonded on 6th anterior mandibular teeth), patients who could be monitored during the first two years of the retention period. Exclusion criteria: patients to whom the finishing phase of orthodontic treatment could not be completed so that the therapeutic outcomes were incorrect, patients who were using fixed retainers with more or less than 6 anterior mandibular teeth, patients who used removable retainers in the lower dental arch. After having applied the inclusion/exclusion criteria, 159 orthodontic patients remained in the study. This sample was divided into three groups depending on the type of fixed retainer that was used: 55 patients (Group 1) with multistranded 0.0195-in wire, 53 patients (Group 2) with Australian 0.020-in wire and 51 patients (Group 3) with laser-sintering retainer.

The study was conducted in accordance to the World Medical Association (WMA) Declaration of Helsinki -

\begin{tabular}{|l|c|c|c|}
\hline Type of material/ Ingredients (\%) & $\begin{array}{c}\text { Stainless } \\
\text { steel } 302\end{array}$ & $\begin{array}{c}\text { Stainless } \\
\text { steel 304 }\end{array}$ & $\begin{array}{c}\text { Starbond CoS } \\
\text { Powder 30 }\end{array}$ \\
\hline IRON (in its oxide form) & Balance & 69.5 & - \\
\hline CHROMIUM & 18.0 & 18.5 & 25.0 \\
\hline COBALT & .75 & .75 & 59.0 \\
\hline NICKEL & 9.0 & 9.0 & - \\
\hline MANGANESE & 2.0 & 1.0 & - \\
\hline WOLFRAM (TUNGSTEN) & - & - & 9.5 \\
\hline MOLYBDENUM & - & - & 3.5 \\
\hline SILICON & - & - & 1 \\
\hline $\begin{array}{l}\text { SILICON, CARBON, PHOSPHORUS, } \\
\text { SULFUR }\end{array}$ & - & Balance & - \\
\hline CARBON, IRON, MANGANESE, AZOTE & - & - & $<1.5$ \\
\hline
\end{tabular}

Table 1

STAINLESS STEEL 302, 304 AND STARBOND COS POWDER 30: COMPOSITION ON INGREDIENTS 
Ethical Principles for Medical Research Involving Human Subjects, approved by the Ethics Committee of the University of Oradea, Romania. All patients were included in the study with their parents' consent.

\section{Material and method}

To assess the anterior-posterior position of lower incisors at the end of orthodontic treatment, we measured the IMPA angle (angle formed by the extension of the mandibular incisor to the mandibular plane, with normal values of $88 \pm 3$ degrees) on the lateral cephalograms [30]. To measure the IMPA values, the authors used a computerized defalcation software, entitled OnyxCeph [open software license (OSL), version 62] (fig. 2-a). In order to analyse the correct alignment of the anterior mandibular teeth at the end of the orthodontic active treatment (prior to the application of the fixed retainer), but also during the first two years of the retention phase in cases with changes in the position of the lower anterior teeth (respectively the cases with relapse) Little's irregularity indexes (LII) were measured on dental casts, introduced by Little R.M. in 1975. The Little' s irregularity index was calculated according to the author's method, based on the linear measurement of displacements in the anatomical contact points of mandihılar five anterinr teeth narallel to the occlusal plane
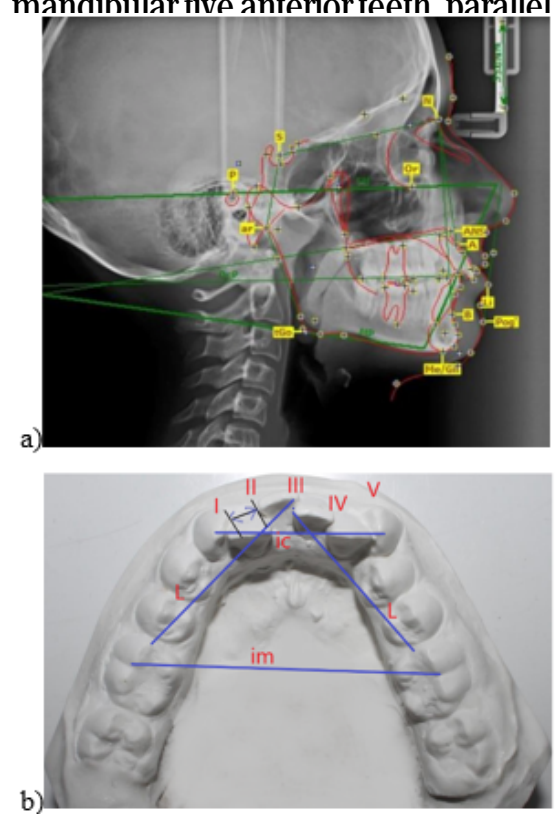

Fig. 2. a)

Cephalometric analysis using OnixCeph; b) Dental cast measurements: Irregularity index $(I+I I+I I+I V+V)$; ic - intercanine width; im - intermolar width; $\mathrm{L}$ - arch length

(fig. 2-b) [31]. We used a digital caliper with a $0.01 \mathrm{~mm}$ sensitivity for these measurements. All cephalometric analyses and dental cast measurements were performed by the same investigator.

After the mechanical removal of the fixed orthodontic appliances with a debonding plier and after the cleaning of residual adhesive from the tooth surfaces, the tooth surfaces were polished with fluoride-free pumice and alginate impressions were poured to obtain the dental casts of the dento-alveolar arches. All retainers in this study were applied on the same day with the debonding of the brackets.

The first step was to adapt the multistrand and Australian wire retainers on dental casts and, respectively, to obtain laser-sintering retainers by a specialised dental

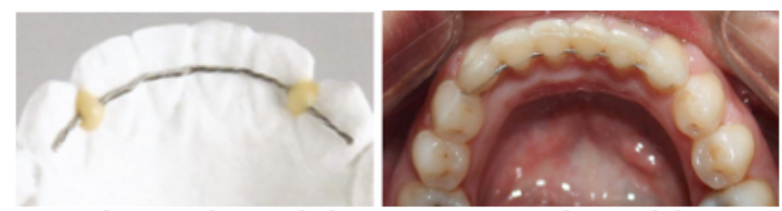

Fig.3. Three multistranded wire retainer on the model cast and intra-oral cavity view

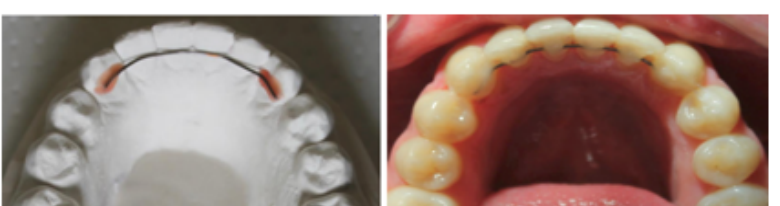

Fig. 4. Australian wire retainer on the model cast and intra-oral cavity view

technician. The multi-stranded wire and Australian wire retainers extend two thirds of the width of the canines

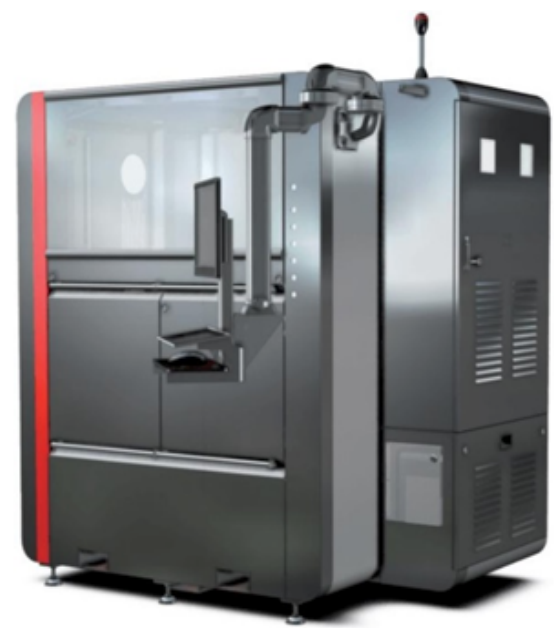

Fig. 5. Prodways PROMaker L5000 D (3D printer) [32]

involved to allow for composite encapsulation of the wire ends (fig. 3, fig. 4).

The Laser sintering retainer is obtained using SLS technology and a special machine (fig. 5) [32] .

First, the digital retainer was obtained using the 3-shape appliance designer software and it was conformed in contact with the lingual surfaces of the anterior mandibular teeth (fig. 6-a). The digital retainer thus obtained was exported, following the physical construction phase with the help of laser sintering technology. In the synthesis process, a laser beam, guided by a computer on a wellestablished path, welds the metal particles, forming the desired product layer by layer (fig 6-b). At the end of the

a)
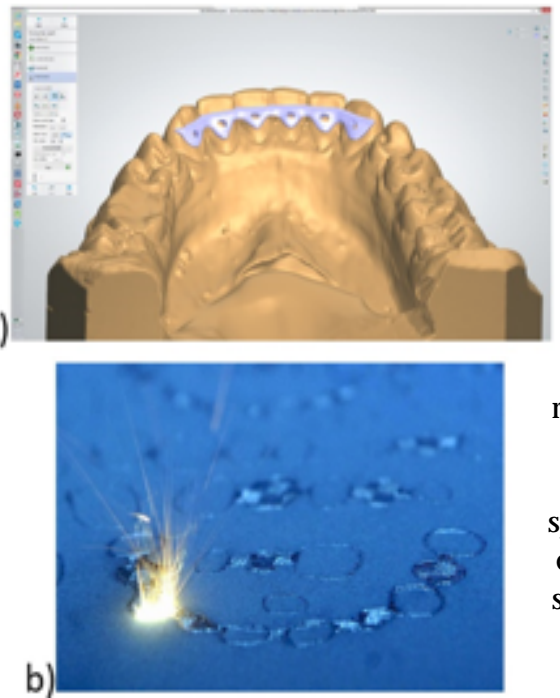

Fig. 6. a) Digital retainer on virtual model; b) The beginning of the synthesis process; c) The end of the synthesis process 
synthesis process, the excess powder was removed, thus preparing the product for the final stage, removing it from

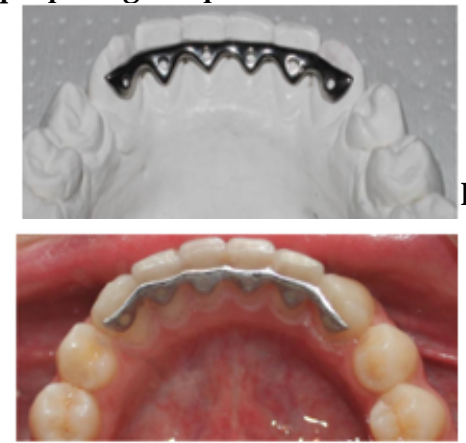

Fig. 7. Laser-sintering retainer on the dental model and intra-oral cavity view

the construction platform, followed by its polishing and ultrasonically cleaning (fig. 6-c).

The final aspect of the laser sintering retainer is presented in figure 7.

All these three types of retainers were bonded to the mid third of the lingual surfaces of each tooth in the anterior segment with composite. Both multistrand and Australian wire retainers were assisted by dental floss using a common technique for these types of retainers. The laser sintering retainers were directly applied in one step after their composite loading. We used the same type of light-curing composite resin for each type of retainers under dry field condition, as follows: the enamel was etched with 37\% phosphoric acid on the lingual surfaces of the lower anterior teeth for 30 seconds (s), rinsed with water for 30 s and dried with air-spray for another 15s, followed by the application of a thin layer of bonding with the micro-brush and light-curing for 10 s, application of the flow composite over the retainer on each of the above mentioned lingual surfaces respecting the interdental areas (keeping the contact points of the mandibular incisors and canines without the wire) and finally light-curing it for 20 s on each composite pad [17,33]. The gingival and subgingival area was also checked for any bonding or composite excess.

We analysed the following undesirable behaviours of the fixed retainers:
- partial detachment - detachment of the retainer at the level of some teeth, the retainer being still on the dental arch;

- total detachment - patients presented themselves without the retainer on the dental arch;

- deformation - patients presented themselves with the retainer bonded on the teeth, but with deformed retainer (always accompanied by relapse);

- breakage / fracture of the retainer - the retainer was broken between two teeth;

- relapses - partial or total recurrence.

We followed all these behaviours of the retainers as well as the relapse during the first year of retention (T1) and during the second year of retention (T2).

\section{Data analysis}

All the data from the study was analysed using IBM SPSS Statistics 20. Qualitative variables were written as counts with percentages and were tested using Fisher's Exact Test for evaluating statistical differences between groups.

\section{Results and discussions}

Data from table 2 and figure 8 show the distribution of the patients according to the behaviour of the three types of used retainers and according to the clinical evolution at T1. Differences between groups were not detected as significant according to Fisher's Exact Test $(p=0.209)$, most of the patients having a normal evolution at T1 $(87.3 \%$ Group 1, 88.7\% - Group 2, 90.2\% - Group 3). Only 2 patients (3.6\%) with multistrainded retainer presented deformation. $5.5 \%$ patients from Group 1 and $5.7 \%$ from Group 2 had partial detachment and 3.6\% from Group 1, 5.7\% from Group 2 and $9.8 \%$ from Group 3 had complete detachment at T1, the differences observed weren't statistically significant.

Data from table 3 and figure 9 show the distribution of the patients according to the behaviour of the three types of used retainers and according to the rate of relapse at T1.

\begin{tabular}{|l|c|c|c|c|c|c|c|}
\hline \multirow{2}{*}{ Type of retainer / Evolution } & \multicolumn{2}{|l|}{ Multistrand wire } & \multicolumn{2}{l|}{ Australian wire } & \multicolumn{2}{|l|}{ Laser sintering } & $\mathrm{p}^{*}$ \\
\cline { 2 - 8 } & Nr. & $\%$ & Nr. & $\%$ & Nr. & $\%$ & \\
\hline Normal & 48 & $87.3 \%$ & 47 & $88.7 \%$ & 46 & $90.2 \%$ & 0.209 \\
\hline Partial detachment & 3 & $5.5 \%$ & 3 & $5.7 \%$ & 0 & $0 \%$ & \\
\hline Complete detachment & 2 & $3.6 \%$ & 3 & $5.7 \%$ & 5 & $9.8 \%$ & \\
\cline { 1 - 7 } & 2 & $3.6 \%$ & 0 & $0 \%$ & 0 & $0 \%$ & \\
\hline
\end{tabular}

Table 2

DISTRIBUTION OF PATIENTS ACCORDING TO THE BEHAVIOUR OF THE THREE TYPES OF USED RETAINERS AND ACCORDING TO THE CLINICAL EVOLUTION AT T1

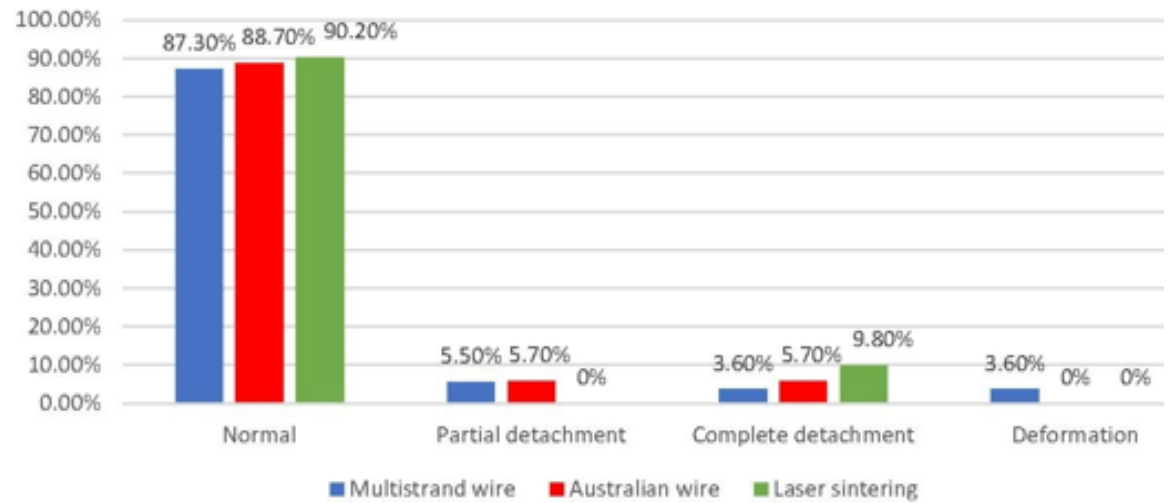

Fig. 8. Distribution of patients according to the behaviour of the three types of used retainers and according to the clinical evolution at $\mathrm{T} 1$ 


\begin{tabular}{|c|c|c|c|c|c|c|c|}
\hline Type of retainer / Relapse & \multicolumn{2}{|l|}{ Multistrand wire } & \multicolumn{2}{l|}{ Australian wire } & \multicolumn{2}{l|}{ Laser sintering } & \multirow{2}{*}{$\mathrm{p}^{*}$} \\
\cline { 2 - 8 } & Nr. & $\%$ & Nr. & $\%$ & Nr. & $\%$ & \\
\hline Without relapse & 49 & $89.1 \%$ & 49 & $92.5 \%$ & 47 & $92.2 \%$ & 0.829 \\
\hline With relapse & 6 & $10.9 \%$ & 4 & $7.5 \%$ & 4 & $7.8 \%$ & \\
\hline
\end{tabular}

Table 3

DISTRIBUTION OF PATIENTS ACCORDING TO THE BEHAVIOUR OF THE THREE TYPES OF USED RETAINERS AND ACCORDING TO THE RATE OF RELAPSE AT T1

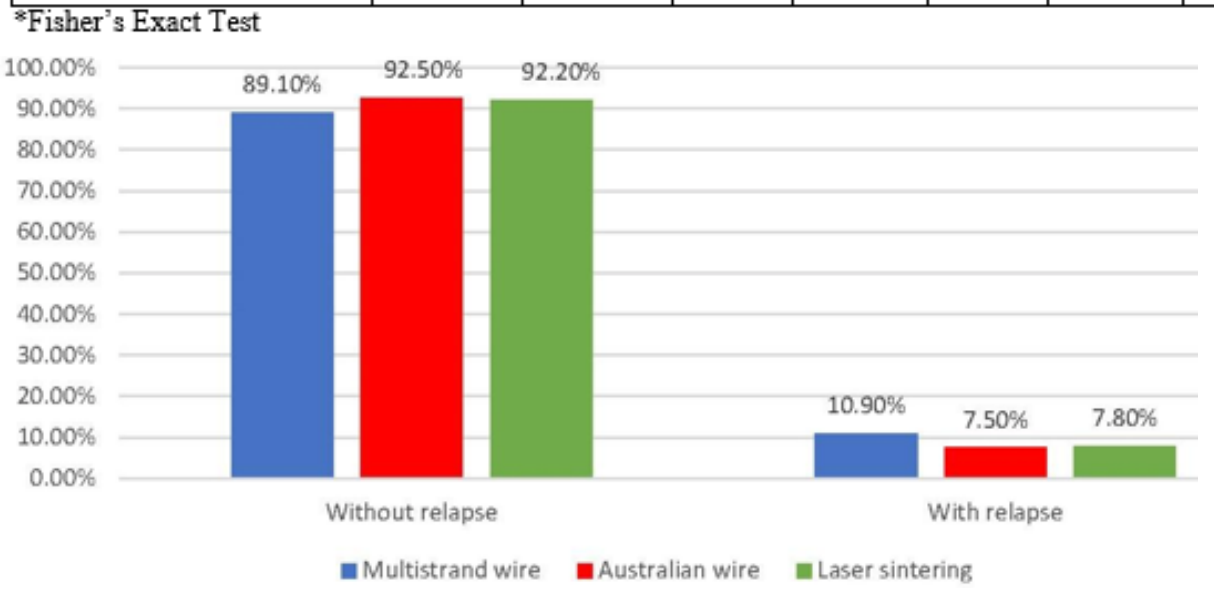

Fig. 9. Distribution of patients according to the behaviour of the three types of used retainers and according to the rate of relapse at $\mathrm{T} 1$

Differences between groups were not detected as significant according to Fisher's Exact Test $(p=0.829)$, a small percentage in each group having relapse $(10.9 \%$ Group 1, 7.5\% - Group 2, 7.8\% - Group 3), the rate of relapse not being significantly different between groups.

After having eliminated the patients with relapse in the first year of retention, the sample was reduced by 14 patients, with 49 patients remaining in Group 1, 49 patients in Group 2 and 47 patients in Group 3.

Data from table 4 and figure 10 show the distribution of the patients according to the behaviour of the three types of used retainers and according to the clinical evolution at T2. Differences between groups were detected as significant according to Fisher's Exact Test $(p=0.018)$, and further Z-tests with Bonferroni correction showed that laser-sintering retainer had a statistically significant better evolution (93.6\%) compared to multistranded retainer
(75.5\%). Only 2 patients (4.1\%) from Group 1 had breakage and other 4 patients ( $8.2 \%$ ) from Group 1 had deformation. 8.2\% from Group 1 and 8.2\% from Group 2 had partial detachment. 4.1\% from Group 1, 6.1\% from Group 2 and $6.4 \%$ from Group 3 had complete detachment at T2, the differences observed weren't significant between these events.

Data from table 5 and figure 11 show the distribution of the patients according to the behaviour of the three types of used retainers and according to the rate of relapse at T2. Differences between groups were not detected as significant according to Fisher's Exact Test $(p=0.464)$, a small percentage in each group having relapse $(14.3 \%$ Group 1, 8.5\% - Group 2, 6.4\% - Group 3), the rate of relapse being not significantly different between groups.

For more than 10 years, we have been using multistranded 0.0195 -in and 0.0215-in wires as bonded

\begin{tabular}{|l|c|c|c|c|c|c|c|}
\hline \multirow{2}{*}{ Type of retainer / Evolution } & \multicolumn{2}{|l|}{ Multistrand wire } & \multicolumn{2}{l|}{ Australian wire } & \multicolumn{2}{l|}{ Laser sintering } & $\mathrm{p}^{*}$ \\
\cline { 2 - 8 } & Nr. & $\%$ & Nr. & $\%$ & Nr. & $\%$ & \\
\hline Normal & 37 & $75.5 \%$ & 42 & $85.7 \%$ & 44 & $93.6 \%$ & 0.018 \\
\hline Partial detachment & 4 & $8.2 \%$ & 4 & $8.2 \%$ & 0 & $0 \%$ \\
\hline Complete detachment & 2 & $4.1 \%$ & 3 & $6.1 \%$ & 3 & $6.4 \%$ \\
\hline Deformation & 4 & $8.2 \%$ & 0 & $0 \%$ & 0 & $0 \%$ \\
\hline Breakage/fracture & 2 & $4.1 \%$ & 0 & $0 \%$ & 0 & $0 \%$ & \\
\hline
\end{tabular}

Table 4

DISTRIBUTION OF PATIENTS ACCORDING TO THE BEHAVIOUR OF THE THREE TYPES OF USED RETAINERS AND ACCORDING TO THE CLINICAL EVOLUTION AT T2

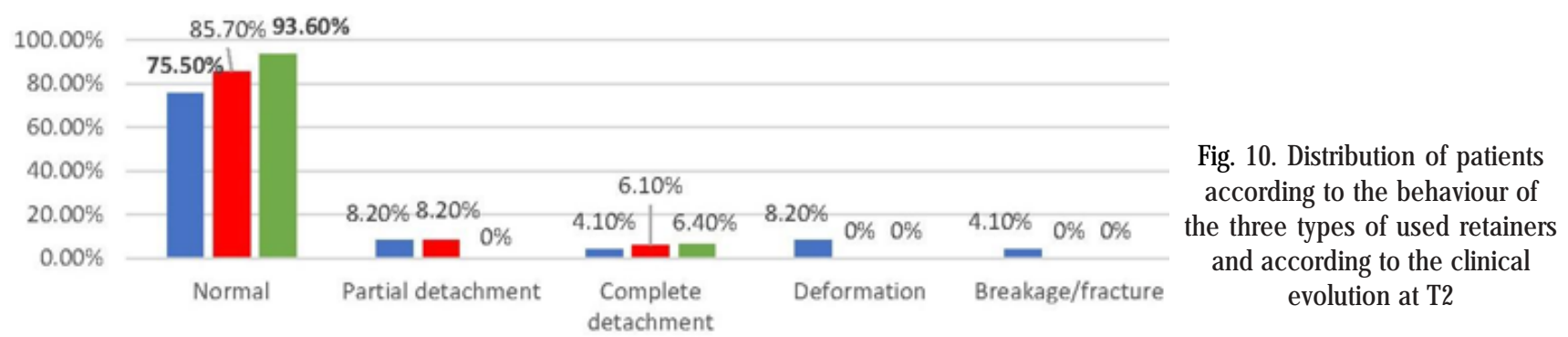


Table 5

DISTRIBUTION OF PATIENTS ACCORDING TO THE BEHAVIOUR OF THE THREE TYPES OF USED RETAINERS AND ACCORDING TO THE RATE OF RELAPSE AT T2

\begin{tabular}{|l|c|c|c|c|c|c|c|}
\hline \multirow{2}{*}{$\begin{array}{l}\text { Type of retainer } \\
\text { Relapse }\end{array}$} & \multicolumn{2}{|c|}{ Multistrand wire } & \multicolumn{2}{c|}{ Australian wire } & \multicolumn{2}{l|}{ Laser sintering } & $\mathrm{p}^{*}$ \\
\cline { 2 - 8 } & Nr. & $\%$ & Nr. & $\%$ & Nr. & $\%$ & \\
\hline Without relapse & 42 & $85.7 \%$ & 43 & $91.5 \%$ & 44 & $93.6 \%$ & 0.464 \\
\hline $\begin{array}{l}\text { With relapse } \\
\text { Fisher's Exact Test }\end{array}$ & 7 & $14.3 \%$ & 4 & $8.5 \%$ & 3 & $6.4 \%$ & \\
\hline
\end{tabular}

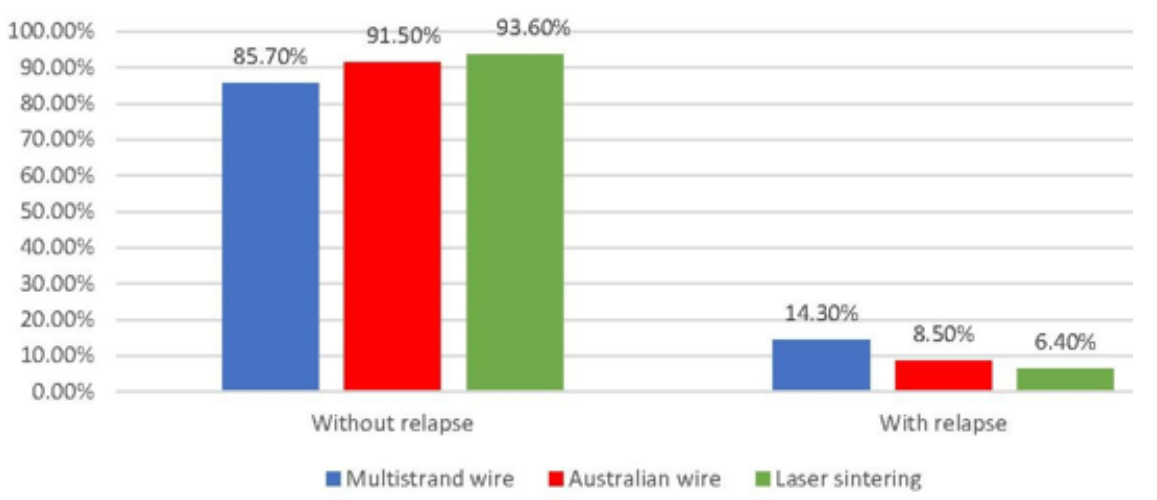

Fig. 11. Distribution of patients according to the behaviour of the three types of used retainers and according to the rate of relapse at $\mathrm{T} 2$

retainers as recommended by the specialised literature. They are more flexible, which allows a correct adaptation to the lingual surfaces of the teeth and a better restructuring of the periodontal structures because they allow some degrees of physiological movement of the retained teeth [34, 35]. The 3-strand 0.0195-in wires are elastic enough to allow for some slight mobility of the individual teeth in a segment unlike the Australian wire and laser-sintering retainers that are rigid. Manufacturers claim that dead-soft wire is superior to five-stranded stainless-steel wire because it is easily adaptable and minimizes the inadvertent tooth movement that is associated with active force wires. Baysal et. al (2012) state that the coaxial wire is recommended as an initial arch wire because it applies light and gentle force. The mastication forces or cleaning of the area beneath the wire with dental floss may cause repetitious deformation that results in the breakage of the retainer wire and wires that are more easily deformed may be more susceptible to breakage [35].

Due to the dissatisfaction with the use of 0.0195 multistrand wire as a fixed lingual retainer over time, in 2015 we decided to introduce the use of Australian wire and laser-sintering retainers as fixed lingual retainers in our current practice.

As far as multistrand retainers are concerned, the most common type of failure was loosening between the composite pad and teeth (3/1 at T2), while for the Australian wire the most common way of failure was loosening between the wire and composite (3/1 at T2). We found wire breakages only in multistrand retainer and only in T2. Lumsden et. al (1999) showed that early breakage is more likely to occur at an adhesive pad than at a wire, and the breakage of the wire breakages appeared only in older retainers [36].

The study shows that the relapse installation rate is similar for all three types of fixed retainers used, slightly reduced at $\mathrm{T} 2$ compared to $\mathrm{T} 1$ only in the case of laser sintered retainers, approximately the same for Australian wire retainers and slightly increased in the second year for multistrand retainers.

Following the clinical observations, we can assess that the relapse installation and its severity are directly proportional to the moment of partial / total detachment, or deformation of the retainer to patients' request for a check-up. There were three patients for whom we were able to re-bond the same total detached retainer, two of them with a laser sintered retainer and one case with Australian wires, the three patients presenting immediately without any relapse installed. Laser-sintering retainers have a more sophisticated technology and are the most expensive but can be reused when patients present themselves in a very short time and no relapse is detected. Laser sintered retainers have the highest complete detachment rate in the first year because they have a greater difficulty in bonding (actually we found the most frequent detachment of these in the first month after their bonding); the risk of detachment of laser sintered retainers is related to the accurate positioning of the retainer, respectively the correct transfer of the position of the retainer from the dental model to the oral cavity. Starbond $\mathrm{CoS}$ laser sintering retainers being Nickel free have the advantage that they can be used in patients allergic to Nickel.

In most of the patients in this study we performed interproximal reduction of the enamel (IPR). In patients with relapse, this was slightly, within Little's index values below $3 \mathrm{~mm}$. Only in the four patients who presented with the deformed retainer, in two patients with complete detachment and in two patients with partial detachment, all with more serious dental changes in the lower dental arch, needed a re-bonding of the fixed orthodontic appliance. All the patients who required re-bonding of the fixed orthodontic appliance presented themselves to the orthodontic service late after the detachment or deformation of the retainer. In other patients with relapse, this could be solved by simple orthodontic means, such as clear aligners or thermo-formed trays made on the set-up dental cast.

This study analysed the effectiveness of three types of fixed retainers that were used in terms of detachment rate and the rate of teeth position alteration, respectively the rate of relapse installation. There are many studies that compare different types of retainers in terms of oral health effects, costs, side-effects, cost-effectiveness, long-term retention capacity $[26,37]$. 
Al Yami et. al (1999) showed that after 10 years of retention, $67 \%$ of orthodontic treatment outcomes are maintained, around half of the total relapse occurs in the first two years of retention, and fixed retainers have a positive effect on the PAR index (Peer Assessment Rating scores) [38].

In a study conducted by Bysal et. al (2012), the authors tested three types of lingual fixed retainers, as follow: 0.0215 -inch five-stranded wire, $0.016 \times 0.022$-inch deadsoft eight-braided wire, and 0.0195-inch dead-soft coaxial wire. The authors concluded that no significant differences were found between the three groups in detachment force or fracture mode [35].

Besides the type and severity of malocclusion, treatment approach, growth and degree of adaptation of the soft tissue, the stability of the orthodontic treatment outcome depends of the type of retention and length of use the retainer [38]. Bonded retainers are especially indicated in patients who initially had severe malpositions, such as severe dental rotations, ectopic or impacted teeth, dental transpositions (these malpositions having a great potential of relapse) [39].

Studies have shown that fixed retainers have the disadvantage of limiting the reorganization of the periodontal ligament and the remodelling of the gingival fibre present in patients with malocclusions and fixed orthodontic treatments $[28,40]$. They also make oral hygiene more difficult compared to removable retainers but have the great advantage of patient comfort. However, the patient should be instructed to properly clean the oral cavity and to insist on the hygiene in the area with the retainer, and be warned about the importance of patientdoctor collaboration and of periodic checks in the retention phase (every three months), especially during the first 2-3 years after orthodontic treatment, in order to minimize the risk of secondary effects of retainers and of relapse [41]. Zachrisson (2015) recommended that the retention period be over 10 years or more, while waiting for the eruption of third molars or until they are germectomized [17]. The extended retention counters the effect of post pubertal growth and maxillo-mandibular adjustments [42, 43]. As long as the retainer remains intact the treatment result is maintained, and if the patient performs adequate plaque control, there is no good reason to remove it [17].

In patients who initially presented class II or III malocclusions (especially skeletal imbalances) for whom the orthodontic treatment included methods for correcting these malocclusions (eg. class II or class III elastics or orthopaedic devises) for the contention of the result we used fixed lingual retainer simultaneously with positioner or removable appliances (such as myobraces/ myofunctional appliances) to stabilize the intermaxillary relationship, the impression of the lower dental arch for making the positioner being taken with the fixed retainer in place $[44,45]$. The fact that these retainers can be worn together with positioners or myobraces is another advantage.

The orthodontist should inform the patient at the beginning of the orthodontic treatment of the need to comply with the retention phase and, in the case of using fixed retainers, the patient should be informed about their risks. We instruct the patient to check the condition of the retainer weekly (regarding partial detachment or deformation), both in the mirror and by finger palpation, and if any minor changes are noticed, request an urgent appointment in the orthodontic service.

Due to some limitations of this study such as the small sample size, short retention periods, no post-retention follow-up periods, we consider thatnew studies with larger sample sizes, longer follow-up periods should be conducted.

\section{Conclusions}

All three types of fixed retention used in this study were similarly effective in the investigated patients in the first year of retention phase. The laser-sintering retainer presented only the complete detachment and it had a statistically significant better evolution compared to multistranded retainer in the second year of retention period. No fixed retention is ideal. The choice for the right retainer needs to be based on the patient's specific needs and on the practioner's experience and judgement. There are cases when they may partially or totally detach and multistranded retainer may be deformed so that they can compromise the correct position of the teeth on which they have been applied.

\section{References}

1.WONG, P.M., FREER, T.J ., A comprehensive survey of retention procedures in Australia and New Zealand. Aust. Orthod. J., 20, no. 2, 2004, p. 99

2.BOOTH, F.A., EDELMAN, J.M., PROFFIT, W.R., Twenty-year followup of patients with permanently bonded mandibular canine-to-canine retainers. Am. J. Orthod. Dentofac. Orthop., 133, no. 1, 2008, p. 70

3.LITTLE, R.M., Clinical implications of the University of Washington post retention studies. J. Clin. Orthod., 43, no. 10, 2009, p. 645

4.TACKEN, M.P., COSYN, J., DE WILDE, P., AERTS, J., GOVAERTS, E., Glass fibre reinforced versus multistranded bonded orthodontic retainers: a 2-year prospective multi-centre study. Eur. J. Orthod., 32, no. 2, 2010, p. 117

5.STORMANN, I., EHMER, U., A prospective randomized study of different retainer types. J. Orofac. Orthop., 63, no. 1, 2002, p. 42 6.VAIDA, L., TODOR, B.I., LILE I.E., MUT, A.M., MIHAIU, A., TODOR L., Contention following the orthodontic treatment and prevalence of relapse. HVM Bioflux, 11, no. 1, 2019, p. 37

7.LITTLEWOOD, S.)., KANDASAMY, S., HUANG, G., Retention and relapse in clinical practice. Aust. Dent. J., 62, no. 1 Suppl., 2017, p. 51 8.THILANDER B., Orthodontic relapse versus natural development. Am. J. Orthod. Dentofacial. Orthop., 117, no. 5, 2000, p. 562 9.PRATT, M.C., KLUEMPER, G.T., HARTSFIELD, J.K.J r, FARDO D., NASH, $D . A$., Evaluation of retention protocols among members of the American Association of Orthodontists in the United States. Am. J. Orthod. Dentofac. Orthop., 140, no. 4, 2011, p. 520

10.KAYA, Y., TUNCA, M., KESKIN, S., Comparison of Two Retention Appliances with Respect to Clinical Effectiveness. Turk. J. Orthod., 32, no. 2, 2019, p. 72

11.AL-MOGHRABI, D., PANDIS, N., FLEMING, P.S., The effects of fixed and removable orthodontic retainers: a systematic review. Prog. Orthod., 17, no. 1, 2016, p. 24

12.VANDEVSKA-RADUNOVIC, V., ESPELAND, L., STENVIK, A., Retention: type, duration and need for common guidelines. A survey of Norwegian orthodontists. Orthodontics (Chic), 14, no. 1, 2013, p. e110

13.VAIDA, L., MOLDOVAN, L., LILE, I.E., TODOR, B.I., PORUMB, A., TIG, I., BRATU, D.C., A comparative study on mechanical properties of some thermoplastic and thermo set resins used for orthodontic appliances. Mat. Plast., 52, no. 3, 2015, p. 364

14.J ADERBERG, S., FELDMANN, I., ENGSTROM, C., Removable thermoplastic appliances as orthodontic retainers-a prospective study of different wear regimens. Eur. J. Orthod., 34, no. 4, 2012, p. 475 15.ZACHRISSON, B.U., BUYUKYILMAZ, T., Bonded retainers. in: Graber, L.W., Vanarsdall, R.L., Vig, K.W., (Eds.) Orthodontics: current principles and techniques. 5th ed. Elsevier Mosby, Philadelphia, 2012, p. 756

16.BECHIR, E.S., PACURAR, M., HANTOIU, T.A., BECHIR, A., SMATREA, O., BURCEA, A., GIOGA, C., MONEA, M., Aspects in effectiveness of 
glass- and polyethylene-fibre reinforced composite resin in periodontal splinting. Mat. Plast., 53, no. 1, 2016, p. 104

17.ZACHRISSON, B.U., Multistranded wire bonded retainers: From start to success. Am. J . Orthod. Dentofac. Orthop., 148, no. 5, 2015, p. 724

18.ZACHRISSON, B.U., Clinical experience with direct bonded orthodontic retainers. Am. J. Orthod., 71, no. 4, 1977, p. 440

19.GREEN, J.I.J., Dental materials: The multi-stranded wire retainer. BDJ Team, 1, 2015, Article number: 15054

20.*** World Famous A.J. Wilcock Australian Wire, G\&H Wire Company. Available at: http://www.ghwire.com/orstore/sal.aspx.

21.*** Material safety data sheet directive 91/155/EEC. Available at: www.ghorthodontics.com/pdf/MSDS/SS_304.pdf

22.*** Starbond CoS Powder. Available at: www.scheftner.dental/ starbond-cos-powder-en.html

23.JIA, L.B., WANG, X.C., WANG, X.J., XU, B., WEI, J., The research and application progress of selected laser sintering technology. Inf. Technol. Informatiz., 11, 2015, p. 172

24. YU, Y.Q., GUO, Y.L., J IANG, T., LI, J ., J IANG, K.Y., ZHANG, H., Study on the ingredient proportions and after-Treatment of laser sintering walnut shell composites. Materials (Basel), 10, no. 12, 2017, p. 1381 25.*** Co-Cr Powder. Available at: www.scheftner.dental/cocrpowder.html

26.LITTLEWOOD, S.J., MILLETT, D.T., DOUBLEDAY, B., BEARN, D.R., WORTHINGTON, H.V., Retention procedures for stabilising tooth position after treatment with orthodontic braces. The Cochrane database of systematic reviews, 29, no.1, 2016, p. CD002283

27.VAIDA, L., PIRTE, A., COREGA, C., SLAVESCU, D., MUTIU, G., Correlations between the changes in patients' facial morphology at the end of the orthodontic treatment and the psychological variables, Rom. J. Morphol. Embryol., 50, no.4, 2009, p. 625

28.VAIDA, L., COREGA, C., ROSEANU, G., Letter to editor: Researches regarding current self-related cognitions in patients with orthodontic treatment, J. Cogn. Behav. Psychot., 9, no. 2, 2009, p. 131

29.COOKE, M.E., SHERRIFF, M., Debonding force and deformation of two multi-stranded lingual retainer wires bonded to incisor enamel: an in vitro study. Eur. J. Orthod., 32, no. 6, 2010, p. 741

30.MIETHKE, R.R., BEHM-MENTHEL, A., Correlations between lower incisor crowding and lower incisor position and lateral craniofacial morphology. Am. J. Orthod. Dentofacial. Orthop., 94, no. 3, 1988, p. 231

31.LITTLE, R.M., The irregularity index: a quantitative score of mandibular anterior alignment. Am. J. Orthod., 68, no. 5, 1975, p. 554 32.*** Prodways ProMaker L5000 D. Available at: www.aniwaa.com/ product/3d-printers/prodways-promaker-I5000-d/
33.ROSIANU, R.S., SINESCU, C., NEGRUTIU, M.L., HOSSZU, T., TUDOR, A., PODARIU, A.C., Microscopic assessment of the enamel etching pattern according to different etching times using orthophosphoric acid gels. Mat. Plast., 53, no.1, 2016, p. 153

34.DAHL, E.H., ZACHRISSON, B.U., Long-term experience with directbonded lingual retainers. J. Clin. Orthod., 25, no. 10, 1991, p. 619 35.BAYSAL, A., UYSAL, T., GUL, N., ALAN, M.B., RAMOGLU, S.I., Comparison of three different orthodontic wires for bonded lingual retainer fabrication. Korean J. Orthod., 42, no.1, 2012, p. 39 36.LUMSDEN, K.W., SAIDLER, G., MCCOLL, J.H., Breakage incidence with direct-bonded lingual retainers. Br. J. Orthod., 26, no. 3, 1999, p. 191

37.EDMAN TYNELIUS, G., BONDEMARK, L., LILJA-KARLANDER, $E$., Evaluation of orthodontic treatment after 1 year of retention - a randomized controlled trial. Eur. J. Orthod., 32, no. 5, 2010, p. 542 38.AL YAMI, E.A., KUIJ PERS-JAGTMAN, A.M., VAN'T HOF, M.A., Stability of orthodontic treatment outcome: Follow-up until 10 years postretention. Am. J. Orthod. Dentofacial. Orthop., 115, no. 3, 1999, p. 300

39.VAIDA, L., TODOR, B.I., COREGA, C., BACIUT, M., BACIUT, G., A rare case of canine anomaly - a possible algorithm for treating it, Rom. J. Morphol. Embryol., 55, no. 3 suppl., 2014, p. 1197

40.VAIDA, L., TODOR, B.I., BERTOSSI, D., COREGA, C., Correlations between Stress, Anxiety and Coping Mechanisms in Orthodontic Patients, Iranian J. Public Health, 44, no. 1, 2015, p. 147

41.RICHARDSON, M.E., GORMLEY, J.S., Lower arch crowding in the third decade. Eur. J. Orthod., 20, no. 5, 1998, p. 597

42.THILANDER, B., Dentoalveolar development in subjects with normal occlusion. A longitudinal study between the ages of 5 and 31years. Eur. J. Orthod., 31, no. 2, 2009, p. 109

43.DASCALU, I.T., TUCULINA, M.) ., RAESCU, M., POPESCU, S.M., COREGA, C., VAIDA, L., BOLD, A., Modifications of the marginal paradentium to a case of Angle Class III/1 malocclusion, Rom. J. Morphol. Embryol., 54, no. 3 suppl,, 2013, p. 857

44.VAIDA, L.L., DIMA, R., CUC, E.A., NEGRUTIU, B.M., MOCA, A.E., LILE, I.E., TODOR, B.I., A comparative study on the efficiency of intermaxillary elastics used in the treatment of skeletal class II malocclusions in growing patients. Mat. Plast., 56, no.2, 2019, p. 341 45.ROMANEC, C., DRAGOMIR, B., BICA, C., The Prophylactic Orthodontic Treatment with Removable Appliances in Children. Rev. Chim. (Bucharest), 69, no. 3, 2018, p. 693

Manuscript received: 6.01 .2019 